\title{
FATORES EXPLICATIVOS DO CAPITAL SOCIAL NO EXTREMO OESTE CATARINENSE
}

\author{
EXPLANATORY FACTORS OF SOCIAL CAIPITAL IN THE \\ WEST OF THE STATE OF SANTA CATARINA (BRAZIL)
}

\author{
Alyne Sehnem* \\ Janaina Macke**
}

Restrmo

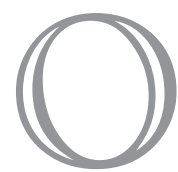
conceito de capital social relacionado com o desenvolvimento econômico de regiões e países começou a ganhar importância na década de 1990. Essa pesquisa tem como objetivo mensurar os níveis de capital social em três regiões das Secretarias de Desenvolvimento Regional do Extremo Oeste de Estado de Santa Catarina (Itapiranga, São Miguel do Oeste e Dionísio Cerqueira). A escolha destas regiões justifica-se também pelo fato de fazerem parte de um dos Programas Regionais promovidos pela Secretaria de Programas Regionais do Ministério da Integração Nacional, o Programa de Promoção do Desenvolvimento da Faixa de Fronteira (PDFF). Para atingir o objetivo do projeto, desenvolveu-se uma pesquisa descritiva, do tipo survey. Os dados passaram por tratamento estatístico utilizando-se a análise fatorial e análise de variância. Os resultados apontam três tipos de capital social (bonding, bridging e linking) em três níveis de análise (micro, meso e macro).

Palavras-chave: Capital Social. Fatores Explicativos. Desenvolvimento Local. Survey. Brasil.

\section{Abstract}

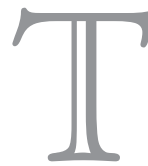

he social capital concept relating to the economic development of regions and countries began to gain importance in 1990 . This research aims to measure the levels of social capital in three regions of the Far West State of Santa Catarina (Itapiranga, São Miguel do Oeste, and Dionísio Cerqueira). The choice of these regions stems from the fact that they are part of one of the programs promoted by the Regional Program of the Ministry of National Integration Secretariat (the Program for Promotion of Border Range Development). A survey was conducted to reach the objective of this project. The data were submitted to statistical analysis using factor analysis and analysis of variance. The results show three types of social capital (bonding, bridging, and linking) on the three levels of analysis (micro, meso, and macro).

Keywords: Social Capital. Factors. Local Development. Survey. Brazil.

* Mestre em Administração (UCS), professora dos Cursos de Administração e Sociologia da Universidade do Oeste de Santa Catarina. Maravilha, SC.

E-mail:adm.alynesehnem@gmail.com

** Pós-doutorado em Desenvolvimento Territorial (bolsista CAPES), pela Université Joseph Fourier (Grenoble/França). Professora do Programa de Pós-graduação em Administração da Faculdade Meridional (IMED), Passo Fundo, RS e da Universidade de Caxias do Sul (UCS), Caxias do Sul, RS. E-mail: janaina.macke@imed.edu.br 


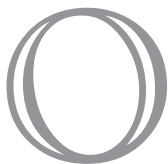

conceito de capital social relacionado com o desenvolvimento econômico de regiões e países começou a ganhar importância na década de 1990, com a obra de Robert Putnam Making Democracy Work: civic traditions in modern Italy. Nessa obra, Putnam conceituou o capital social como característica da organização social, citando como exemplo a confiança, normas e redes, que podem melhorar a eficiência da sociedade, facilitando ações coordenadas.

No trabalho realizado pelo autor durante duas décadas, constatou-se que a acumulação de capital social marcou o desenvolvimento da região norte da Itália. Por outro lado, a sua carência determinou o atraso econômico observado na região sul (PUTNAM et al., 2002).

O desenvolvimento da presente pesquisa inspirou-se, inicialmente, nas abordagens de Putnam. A experiência catarinense de regionalização iniciada no Oeste do Estado baseou-se no modelo italiano. Outra inspiração para a elaboração desse trabalho foi encontrada nas pesquisas de Monastério (2002; 2003), desenvolvidas com base em Bandeira (1994) e Verschoore Filho (2000). Em suas pesquisas, Monastério (2002; 2003) relacionou indicadores de capital social com indicadores econômicos a fim de explicar as desigualdades de desenvolvimento das regiões do estado do Rio Grande do Sul, com ênfase para a região Sul, conhecida como região da Campanha.

Estudar o capital social, "exige dos pesquisadores posturas plurais e interdisciplinares" (MONASTÉRIO, 2002, p. 7), uma vez que um olhar restrito ao lado econômico limitaria o estudo a ocultar o contexto histórico cultural que se pretende compreender.

Vincular o desenvolvimento local às diferenças e à intensidade do capital social nas regiões é uma questão de debate nos meios acadêmicos. A integração do capital social e da cultura nas discussões acerca do desenvolvimento transforma a discussão sobre as estratégias políticas mais complexas (KLIKSBERG, 1999). Assim, o capital social pode ser entendido como um recurso produtivo à disposição dos indivíduos e com o qual é possível alcançar objetivos, os quais sem ele, não seriam acessíveis (ABRAMOVAY, 2000).

Diante destas constatações, esta pesquisa tem como objetivo mensurar os níveis de capital social em três regiões de Secretarias de Desenvolvimento Regional do Estado de Santa Catarina. Este processo ocorreu por meio da realização de pesquisa do tipo survey com moradores dos municípios pertencentes às regiões das Secretarias de Desenvolvimento Regional da fronteira Oeste do Estado de Santa Catarina (Itapiranga, São Miguel do Oeste e Dionísio Cerqueira).

Referemciall teórrico

A difusão do conceito de capital social no meio acadêmico ocorreu, principalmente, devido: à valorização das relações e estruturas sociais no discurso político; ao reconhecimento dos recursos embutidos em estruturas e redes sociais não contabilizados por outras formas de capital; ao ambiente político-econômico emergente, que levou a um reposicionamento dos papéis do Estado e da sociedade; ao caráter transversal, multidisciplinar e de alavancagem política do conceito (ALBAGLI e MACIEL, 2002).

O termo capital social faz parte das pesquisas desde o início do século XIX. No entanto, somente a partir da década de 1990 o tema passou a receber maior destaque. Nessa época, o Banco Mundial começou a utilizar o conceito de capital social vinculado às questões relacionadas à pobreza, bem como a sua utilização no processo de avaliação dos projetos a ele submetidos. Para o Banco Mundial, o capital social e a cultura são as "chaves para o desenvolvimento"; logo seus projetos devem levar em consideração os valores sociais do meio onde será efetivado (D'ARAúJO, 2003).

Desde o princípio o uso do conceito foi utilizado para elucidar uma gama de fenômenos sociais, no entanto, com o passar dos anos os pesquisadores concentraram sua atenção não só no papel do capital social como influenciador do desenvolvimento do capital humano (COLEMAN, 1988), mas também sobre a sua influência no 
desenvolvimento das regiões geográficas (PUTNAM et al., 2002) e também no desenvolvimento das nações (FUKUYAMA, 2000).

De acordo com Nahapiet e Ghoshal (1998), o capital social pode ser definido como a acumulação dos recursos reais e potenciais incorporados, disponíveis e derivados da rede de relacionamentos possuída por um indivíduo ou unidade social. A unidade social pode ser entendida como uma equipe, grupo ou mesmo uma organização (LEE; SUKOCO, 2007).

Em função da natureza do estudo optou-se por adotar a vertente do capital social no sentido "coletivo", defendido por Coleman, ao invés de trabalharmos esse conceito sob o olhar individual, de acordo com Bourdieu (1986, 1996, 2000). Para Coleman (1990), o capital social possibilita uma melhor compreensão das relações de confiança que se estabelecem entre os grupos que favorecem a ação coletiva organizada. Os indivíduos se utilizam do capital físico e humano para atingir seus objetivos; no entanto, na ação conjunta só satisfazem alguns de seus interesses. As relações sociais possibilitam que as ações conjuntas se estabeleçam, o que só é possível por meio do capital social. O capital social "localiza-se não nos indivíduos, mas nas relações entre eles, e a existência de capital social aumenta os recursos à disposição dos indivíduos que encontram-se imersos em tais relações" (COLEMAN, 1990, p. 300).

$\mathrm{Na}$ vertente do capital social como um recurso coletivo, ele pode ser entendido como um ativo que facilita algumas formas de ação social e inibe outras. As relações sociais, sejam elas entre os membros de uma família ou entre membros de uma comunidade, revelam-se como um fator importante para o desenvolvimento do capital humano. Da mesma forma o capital social exerce influência para o desenvolvimento do capital intelectual (COLEMAN, 1988; NAHAPIET; GHOSHAL, 1998).

Diferentes tipos de capital social foram identificados pelos pesquisadores do tema: bonding social capital (união), bridging social capital (ponte) e linking social capital (ligação) (PASSEY; LYONS, 2006). Os tipos de capital social refletem os diferentes papéis que as redes podem desempenhar no desenvolvimento econômico de uma sociedade (SABATINI, 2008).

O bonding social capital refere-se às relações mais próximas dos indivíduos. É caracterizado pelos laços fortes existentes entre os grupos de pessoas que partilham valores semelhantes, como por exemplo, nas relações entre familiares e amigos, pessoas mais próximas do círculo de convivência. Devido a essa proximidade os indivíduos refletem semelhanças nos hábitos e comportamentos (MACKE et al., 2010).

Esse tipo de capital social pode restringir-se a um grupo limitado, não se expandindo para outros grupos que estejam fora do espaço local (WEBB, 2008; MACKE et al., 2012; DE CAROLIS; SAPARITO, 2006). Esses grupos, considerados "fechados", podem ter maior facilidade no desenvolvimento do capital social, especialmente nas dimensões relacional e cognitiva, uma vez que dificultam a participação de não membros no espaço do grupo. No entanto, essa característica propicia o isolamento, pelo fato de o grupo construir normas e uma identidade própria, desenvolver a confiança entre os membros e um código de linguagem particular. Para Sabatini (2008), o termo bonding detém uma conotação negativa e geralmente refere-se a pequenos círculos de pessoas que não cooperam com outras que estejam fora dos limites do seu grupo.

Assim, o tipo bonding do capital social acontece nas relações entre grupos homogêneos, tais como membros da família e amigos próximos; refere-se a o que Granovetter (1985) considera serem os laços fortes. Os laços fortes são característicos de comunidade ou grupos fechados. Esses grupos desenvolvem o capital social basicamente em sua dimensão relacional e cognitiva. Desenvolvem-se de maneira isolada, "excluindo" ou impondo barreiras à entrada de elementos que não pertencem a seu grupo. As normas, identidade e confiança desenvolvidas pelas comunidades ou grupos fechados proporcionam um isolamento desse grupo e a criação de códigos de comunicação próprios a eles (NAHAPIET; GHOSHAL, 1998; MACKE et al., 2010).

Por outro lado, os laços fracos são próprios de comunidades com grande tolerância e iniciativa pessoal. Eles têm como característica a possibilidade de unir diferentes grupos, ao contrário dos laços fortes que estimulam a cooperação dentro 
dos grupos, os laços fracos desempenham a função de ligar os grupos e promover a cooperação entre eles (WEBB, 2008; MACKE et al., 2010).

O bridging social capital representa a conexão existente entre os diferentes grupos, tais como os amigos dos amigos, os sócios, os conhecidos. Esse tipo de capital social descreve os laços horizontais das pessoas com grupos de diferentes origens (MACKE et al., 2010). O termo bridging remete à capacidade dessas redes de criar "pontes" ligando diferentes grupos sociais, entre as gerações, grupos culturais, étnicos e religiosos que, de outra forma, dificilmente teriam entrado em contato (DE CAROLIS; SAPARITO, 2006; SABATINI, 2008). Este tipo de capital social tem efeitos positivos sobre a difusão das informações e da confiança, promovendo as operações e a atividade econômica (MACKE et al., 2010).

O capital social do tipo bridging assume a forma de laços mais fracos que atravessam os grupos sociais e são mais comumente encontrados em modernos cenários urbanos (PASSEY; LYONS, 2006). Além dos laços serem geralmente mais fracos, podem ser também menos intensos (CRAWFORD, 2006).

Por fim, o linking social capital refere-se à ligação existente entre os vínculos do capital social que conectam pessoas (ou o grupo a que pertence) a pessoas ou grupos em situação de poder político ou financeiro. Esse tipo de capital social é bom para acessar instituições formais, podendo fomentar a ligação intra e intergrupos do bridging (SABATINI, 2008; CRAWFORD, 2006; WEBB, 2008).

Considera-se também que o capital social do tipo linking está relacionado às relações entre os indivíduos e grupos em diferentes estratos sociais, ou seja, em uma hierarquia onde o poder, status social e riqueza são acessados por diferentes grupos. Este tipo de capital social permite a unificação do capital social coletivo com a visão do capital social individual (MACKE et al., 2012). Neste tipo de capital social está presente a capacidade de alavancar recursos, ideias e informações para além das instituições formais da comunidade (NATIONAL STATISTICS, 2001).

A revisão da literatura sobre capital social caracteriza o bonding como uma "cola social" e o bridging como o "óleo social". O linking é incorporado pelos laços entre os indivíduos e organizações ocupando diferentes níveis de poder ou de status, que muitas vezes são mediados pelas instituições (PASSEY; LYONS, 2006; DE CAROLIS; SAPARITO, 2006).

Para estrutura a coleta de dados do presente estudo, utilizamos a matriz conceitual do capital social segundo David Halpern (2008). Esta matriz permite visualizar as redes sociais, normas e sanções que facilitam a ação cooperativa entre os indivíduos e comunidades. Para Halpern (2008), qualquer estrutura social que facilita a cooperação e a confiança entre os indivíduos pode ser considerada como uma forma de capital social.

Conforme pode ser observado na Figura 1, Halpern (2008) trabalha com a existência de três dimensões transversais do capital social: componentes, níveis de análise e funções. Os componentes do capital social, que interagem, influenciam e reforçam-se mutuamente, consistem em redes (relações de interconexão entre os indivíduos), normas (regras, valores e expectativas que norteiam as relações sociais) e sanções (punições e recompensas).

Os níveis de análise do capital social dividem-se em micro, meso e macro. No nível micro, o capital social é constituído pelos estreitos laços com a família e com os amigos. O nível meso caracteriza as comunidades e organizações associativas e o nível macro do capital social refere-se às relações de nível estadual e nacional. Para o autor, existem equivalências funcionais entre os diferentes níveis, ou seja, a diminuição do capital social em um nível pode ser compensada pelo aumento em outro nível (HALPERN, 2008).

As principais funções do capital social para Halpern (2008) são conhecidas também como tipos de capital social: bridging, bonding e linking.

Para Halpern (2008), há inter-relação entre os três aspectos de cada dimensão (redes, normas e sanções; níveis micro, meso e macro; tipos bridging, bonding e linking), assim como há relação entre as três dimensões (componentes, níveis de análise e funções). A compreensão destas inter-relações pode orientar melhor a análise do capital social. 
Figura 1 - Matriz conceitual do capital social

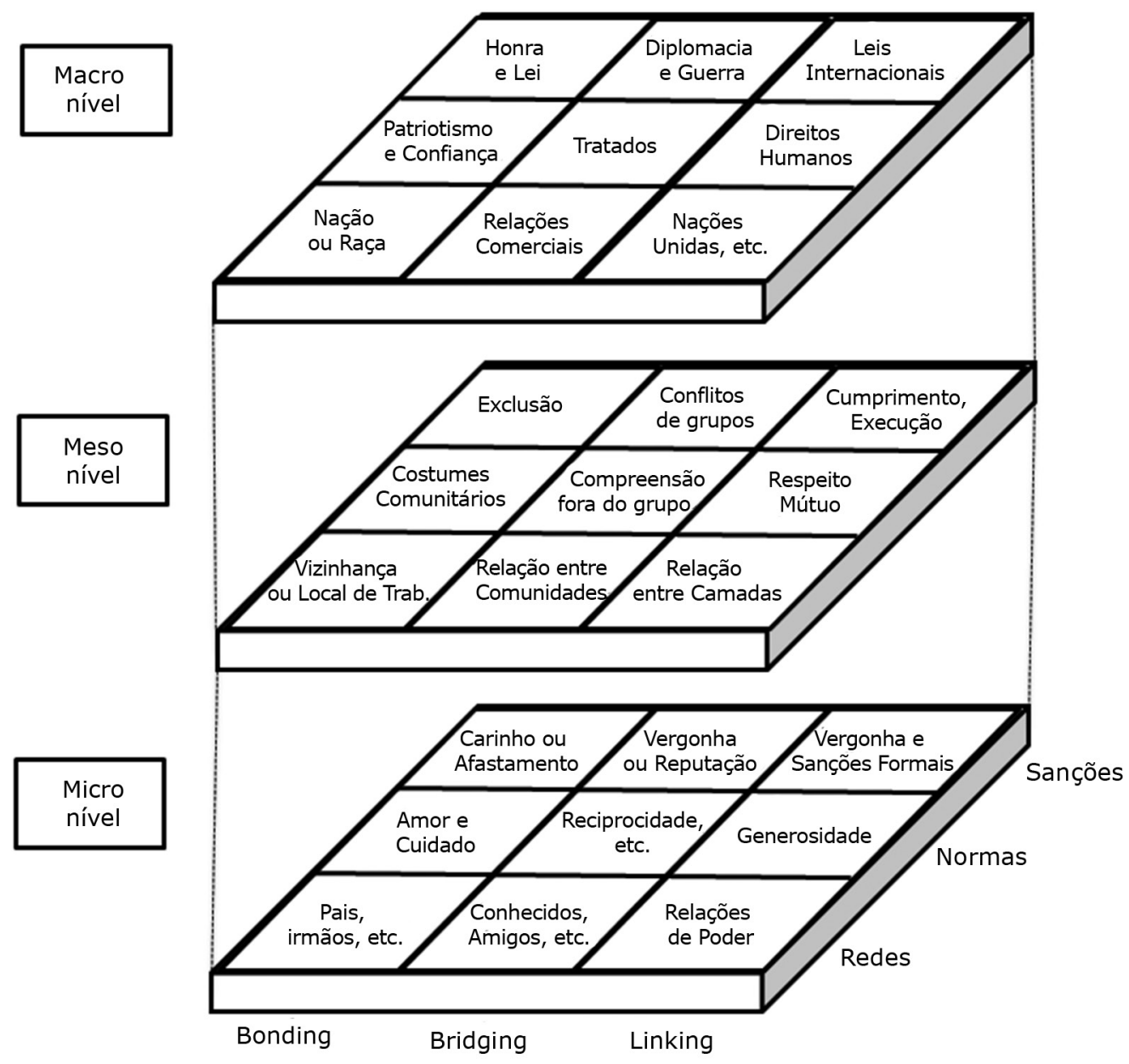

Fonte: Halpern (2008, p. 27).

Dessa forma, Halpern (2008) percebe uma transformação do capital social quando muitos estudiosos visualizam um declínio. Ele reconhece que há um declínio em certas formas de capital social; no entanto, ele identifica um aumento em outras formas. Assim, o autor mostra-se preocupado com as consequências que essas transformações podem causar, uma vez que afetam a prosperidade econômica, a saúde e o bem-estar, a criminalidade, a educação e a legitimidade do governo de diferentes formas.

\section{Miérodlo dlat pesqurisal}

A pesquisa se propôs a desenvolver um novo instrumento de mensuração de capital social e a aplicar este instrumento nos municípios de abrangências das três Secretarias de Desenvolvimento Regional da região do Extremo Oeste de Santa Catarina. Para a mensuração do capital social nos municípios, utilizou-se a técnica de pesquisa por survey, ou seja, a mensuração de amostras por meio de questionários autoadministrados aplicados junto às comunidades (HAIR JUNIOR et al., 2007).

Assim, a análise dos dados obtidos por meio da pesquisa foi realizada utilizando a ferramenta estatística de análise fatorial. Também, ao final da análise procurou-se 
verificar quais características dos respondentes poderiam afetar os fatores de capital social encontrados. Para isso, foi utilizada a análise de variância do tipo ANOVA. Os resultados foram analisados por meio do software SPSS (Statistical Package of Social Science), versão 17.0 .

Por análise fatorial entende-se como a técnica utilizada para "sintetizar as informações de um grande número de variáveis em um número bem menor de variáveis e fatores" (HAIR JUNIOR et al., 2007, p. 321). A análise de variância (ANOVA) é um teste realizado para avaliar as diferenças estatísticas existentes entre as médias de dois ou mais grupos. Para a análise dos resultados da ANOVA considera-se que $p<$ 0,05 , ou seja, quando $p$ é menor que 0,05 a diferença das médias dos respondentes é estatisticamente significativa (HAIR JUNIOR et al., 2007).

\section{Definição da Âreal e Plano dle Amostragern}

Para a realização do cálculo que definiu o número de pessoas que fizeram parte da pesquisa, utilizou-se a técnica de amostragem não probabilística estratificada, na qual "o número de objetos ou unidades de amostragem escolhidos em cada um dos grupos é proporcional ao número na população" (AAKER et al., 2004). Para a obtenção da quantidade de questionários que deveriam ser aplicados nos municípios abrangidos pelas Secretarias de Desenvolvimento Regional de Itapiranga, São Miguel do Oeste e Dionísio Cerqueira foram utilizados os dados referentes à contagem da população, realizada pelo IBGE no ano de 2007, que determina o número de habitantes de cada município e a sua discriminação por gênero.

A quantidade de questionários foi definida levando-se em consideração uma população finita de 151.854 habitantes. A confiança desejada para essa pesquisa foi de $95 \%$ e o erro amostral considerado foi de $5 \%$. A amostra resultante foi de 385 participantes.

Como orientação geral, o tamanho da amostra deve ser, no mínimo, quatro a cinco vezes mais observações (tamanho da amostra) do que variáveis. Dessa forma, foi aplicado o instrumento com 63 questões de mensuração do capital social, mais 14 questões gerais de identificação da população. De acordo com o tamanho sugerido por Malhotra (2007), a amostra da pesquisa (quatro a cinco vezes mais observações do que variáveis) deveria realizar 315 observações (considerando cinco vezes 63 variáveis de capital social).

Optou-se por arredondar a amostra para 400 questionários distribuídos nos municípios de acordo com os dados do IBGE no que tange ao número de habitantes, gênero, local de moradia, renda e escolaridade. No entanto, com o intuito de garantir a confiabilidade do instrumento, foram distribuídos 530 questionários, dos quais retornaram 512 e foram considerados válidos 499.

Para a amostragem, considerou-se como critérios de estratificação: gênero, idade, escolaridade e local de moradia (rural ou urbano). A proporcionalidade com relação ao gênero e local de moradia dos habitantes da região é próxima aos $50 \%$. Dessa forma, optou-se por observar essa proporção entre os participantes da pesquisa: aproximadamente $50 \%$ do gênero feminino e masculino e, aproximadamente, $50 \%$ moradores da zona urbana e $50 \%$ da zona rural.

Aspectos referentes à faixa etária e à escolaridade também foram observados a fim de que a pesquisa refletisse com maior fidedignidade as características da região. Com relação à escolaridade, foi levada em consideração uma proporcionalidade de formação escolar de acordo com a população, para evitar vieses.

Instriminernto de Colleta de Dados

Foi analisado para a mensuração do capital social nessa pesquisa o Questionário Integrado para Mensuração do Capital Social, instrumento de coleta de dados utilizado pelo Banco Mundial (2009) para mensuração do capital social em países. Esse instrumento mostrou-se complexo e extenso para a realidade deste estudo. Outro instrumento analisado foi encontrado no banco de dados da Saguaro Seminar (BETTERTOGETHER, 2009). 
Da mesma forma com que pesquisas anteriores tiveram contribuição significativa para essa pesquisa, convém ressaltar que pesquisas futuras serão desenvolvidas tendo como base o instrumento desenvolvido para a coleta de dados nos municípios da região das SDRs do Extremo Oeste Catarinense. A utilização do instrumento criado a partir da matriz do capital social de Halpern (2008) tem como intuito a construção de instrumento adaptado à realidade brasileira. Apesar disso, prezou-se pela inclusão de afirmativas de características histórico-culturais da região em que o questionário seria aplicado. Esse aspecto possibilitou um retrato mais próximo da realidade dos municípios pesquisados.

Sendo assim, o questionário foi aplicado em 18 municípios da região de estudo, no período de junho a agosto de 2010. Foi elaborado tendo como base a matriz conceitual do capital social elaborado por Halpern (2008), as pesquisas de Onyx e Bullen (2000), Gaag e Snijders (2003), Monastério (2003) e Macke et al. (2012). Dessa forma o questionário foi composto por 63 questões, além das 14 questões gerais de identificação da população.

Enfatiza-se que, antes da aplicação definitiva do questionário, foi realizado um pré-teste com 30 questionários, a partir do qual foi possível identificar falhas na redação do questionário e, a partir disso, melhorar a clareza das questões para o público que se pretendeu investigar.

Fartores dlo calpitall sociall mal região do extremo oeste de Sarntal Cartaninal

Para verificar a medida de consistência interna de escalas de múltiplos itens, utiliza-se o Alfa de Cronbach, o qual deve ficar entre 0,70 e 1,00 para ser considerado aceitável (PESTANA; GAGEIRO, 2000). Já para Malhotra (2007) e Hair Junior et al. (2007), alfas superiores a 0,5 são considerados apropriados para pesquisas exploratórias nas ciências sociais. O alfa encontrado na análise fatorial de todo o instrumento de pesquisa foi de 0,766 , considerado, portanto, aceitável. Esse resultado demonstra que há consistência interna no instrumento como um todo.

Um dos resultados alcançados foi a verificação de quais variáveis de identificação dos respondentes (sociais, econômicas e demográficas) são estatisticamente significativas para os fatores encontrados. Na Figura 2, é possível verificar as variáveis que apresentaram diferenças significativas (teste de diferença de médias do tipo ANOVA) de acordo com os fatores encontrados.

As setas indicam, por exemplo, que o capital social aumenta com o tempo de bairro (micro bonding). Cabe chamar a atenção que a variável renda não apresentou diferenças significativas para nenhum dos fatores encontrados. Isso mostra que o capital social na região é um recurso que independe da condição econômica da população - ele está presente em todos os estratos sociais. As implicações destes resultados são detalhadas a seguir, juntamente com as variáveis que compõem cada um dos fatores de capital social encontrados no estudo.

Capitarl sociall em mivell micro

Os dados foram submetidos à análise fatorial utilizando PCA (Análise de Componentes Principais), com rotação varimax e tratamento pairwise (considerado todas as observações válidas de cada variável) para dados omissos. O índice de Kaiser-Meyer-Olkin (KMO) de adequação da amostra foi de 0,653 e Teste de Bartlett de esfericidade (significativos para 0,000 ) indicaram a fatorabilidade dos dados.

O resultado da análise fatorial indicou que o capital social é explicado por três fatores, com $51,64 \%$ da variância total explicada. Alpha de Cronbach para esta escala foi 0,602 , que representa um intervalo satisfatório para um estudo exploratório (HAIR et al., 2007). É possível concluir que os itens em cada dimensão da construção são adequados para medir o capital social nas comunidades (Tabela 1). 
Figura 2 - Variáveis que apresentaram diferenças estatisticamente significativas

\begin{tabular}{|c|c|c|c|}
\hline & Bonding & Bridging & Linking \\
\hline Micro & $\begin{array}{c}\text { SDR - Itapiranga } \uparrow \\
\text { Tempo de bairro } \uparrow \\
\text { Idade } \downarrow \\
\text { Residência - alugada } \downarrow \\
\text { Trabalho - do lar } \uparrow \\
\text { Vínculo com a cidade - avós } \\
\text { já viviam na cidade } \uparrow\end{array}$ & $\begin{array}{c}\text { SDR - Dionísio Cerqueira } \uparrow \\
\text { São Miguel do Oeste } \uparrow \\
\text { Tempo de bairro } \uparrow \\
\text { Gênero - feminino } \uparrow \\
\text { Estado civil - solteiro } \uparrow\end{array}$ & $\begin{array}{c}\text { SDR - Dionísio Cerqueira } \uparrow \\
\text { Gênero - feminino } \uparrow \\
\text { Estado civil - solteiro } \uparrow \\
\text { Ter filhos } \uparrow \\
\text { Trabalho - formal } \uparrow \\
\text { Expectativa de continuar } \\
\text { morando na cidade } \uparrow\end{array}$ \\
\hline Meso & $\begin{array}{c}\text { Tempo de bairro } \downarrow \\
\text { Gênero - feminino } \uparrow \\
\text { Escolaridade - nível médio } \downarrow\end{array}$ & $\begin{array}{c}\text { Ter filhos } \uparrow \\
\text { Expectativa de continuar } \\
\text { morando na cidade } \uparrow\end{array}$ & $\begin{array}{c}\text { Zona - urbana } \uparrow \\
\text { Idade - dos } 30 \text { aos } 49 \text { anos } \downarrow \\
\text { Ter filhos } \downarrow \\
\text { Residência - emprestada } \uparrow \\
\text { Trabalho - formal } \uparrow\end{array}$ \\
\hline Macro &.-- & $\begin{array}{c}\text { SDR - Itapiranga } \uparrow \\
\text { Zona - rural } \uparrow \\
\text { Residência - própria } \uparrow \\
\text { Expectativa de continuar } \\
\text { morando na cidade } \uparrow\end{array}$ & $\begin{array}{c}\text { SDR - Itapiranga } \uparrow \\
\text { Ter filhos } \uparrow \\
\text { Residência - própria } \uparrow\end{array}$ \\
\hline
\end{tabular}

Fonte: presente estudo.

Tabela 1 - Fatores, Alfa de Cronbach, cargas e médias no nível micro do capital social

\begin{tabular}{|c|c|c|c|c|}
\hline Fator & Alpha de Cronbach & Variável & Carga & Média \\
\hline \multirow{3}{*}{ Linking } & \multirow{3}{*}{0,564} & 9 - Eu faço doações a quem precisa & 0,760 & 3,61 \\
\hline & & 2 - Ficar com a família & 0,712 & 4,30 \\
\hline & & 18 - Faço trabalhos voluntários & 0,683 & 3,36 \\
\hline \multirow{3}{*}{ Bonding } & \multirow{3}{*}{0,517} & 17 - Ajudo amigos, pois posso precisar deles & 0,760 & 4,64 \\
\hline & & 7 - Cuido de minha família, pois posso precisar dela & 0,706 & 4,47 \\
\hline & & 10 - Ajuda de amigos para tomar decisões importantes & 0,619 & 4,10 \\
\hline \multirow{3}{*}{ Bridging } & \multirow{3}{*}{0,412} & 14 - Amigos de diferentes classes sociais & 0,727 & 4,59 \\
\hline & & 16 - Estabelecimentos que vendem na caderneta & 0,698 & 4,31 \\
\hline & & 1 - Contato com amigos & 0,553 & 4,40 \\
\hline
\end{tabular}

Fonte: presente estudo.

O primeiro fator encontrado foi o linking social capital, considerado, assim, o fator mais forte na explicação do capital social em nível micro (evidenciado também através das cargas fatoriais das variáveis: duas maiores de 0,7 e uma muito próxima de 0,7). 
A correlação com valor mais alto nesse fator foi encontrada na variável que demonstra a participação em campanhas de solidariedade (com carga fatorial de 0,760 ).

Ao primeiro olhar, ao nível micro, poderia esperar-se que o tipo que mais se destacasse fosse o bonding, uma vez que se refere às relações estabelecidas entre grupos de amigos e familiares. No entanto, o destaque obtido pelo tipo linking pode ser entendido pelas relações hierárquicas que se estabeleceram/estabelecem entre pais e filhos, resultando num distanciamento e numa maior formalidade nos relacionamentos. Essas características podem ser observadas nas pessoas de origem europeia, que costumam prezar mais pelo trabalho e religiosidade, do que por demonstrações de afeto (EIDT, 2009).

O segundo fator analisado, denominado de bonding social capital, é constituído pelas variáveis que se reportam ao relacionamento nos grupos familiar e de amigos. Os elementos que compõem esse tipo de capital social são: ajudar amigos (carga de 0,760 ), cuidar da família (carga de 0,706 ) e pedir conselhos a amigos e conhecidos (carga de 0,619). A prática de ajudar os amigos para um dia contar com a ajuda dos mesmos obteve o melhor desempenho de todo o nível micro (média de 4,64). Estes resultados podem ser explicados pelas características culturais da região estudada. Os municípios da região da fronteira oeste de Santa Catarina foram colonizados por imigrantes do Rio Grande do Sul a partir da década de 1920. As famílias colonizadoras valorizavam e preservavam as relações familiares e o respeito aos mais velhos, que são pessoas com maior experiência de vida e capazes de auxiliar e aconselhar os mais novos em suas atividades e decisões (EIDT, 2009). As variáveis da pesquisa demonstram essa realidade também para as gerações mais novas, sendo uma prática ainda nos dias de hoje. Estes elementos estão presentes nas manifestações e comemorações realizadas com frequência na região, tais como romarias, festas de padroeiro e semanas típicas, onde são realizadas atividades visando relembrar o cotidiano dos colonizadores (por exemplo, Deucht Woche - Semana Alemã) (SEHNEM, 2009).

O capital social do tipo bridging constitui o terceiro fator de análise. As variáveis encontradas mostram que no grupo pesquisado as pessoas possuem amigos de diferentes classes sociais (carga 0,727 ), há a prática de comprar na caderneta em mercados locais (carga 0,698 ) e as pessoas se esforçam para manter contato com os amigos (carga 0,553). Esses elementos destacam a existência de normas de reciprocidade e de sanções implícitas nos grupos. As normas de reciprocidade explicitam as tradições, valores e crenças existentes nos grupos e que são seguidos pelos seus membros de maneira a manter boas relações e facilitar a cooperação dentro e entre os grupos.

O fato de tratar-se de municípios pequenos nos quais as pessoas se conhecem e vivem na mesma cidade há anos (que contribui para que o capital social do tipo bonding apresente maior força que o tipo bridging), propicia o surgimento e a valorização das normas de reciprocidade. Essas características dos grupos fazem com que a reciprocidade seja observada e controlada pelos membros do grupo; as pessoas se sentem responsáveis e zelam umas pelas outras, reproduzindo a prática conhecida como "olhos na rua" (FUKUYAMA, 2000).

O bridging social capital tem efeitos positivos sobre a difusão das informações e da confiança, promovendo as operações e a atividade econômica. A confiança pode ser conceituada como um sentimento de expectativa positiva e a crença de que um indivíduo vai se comportar de uma forma benéfica (ROUSSEAU et al., 1998; DE CAROLIS; SAPARITO, 2006). A confiança surge a partir de repetidas interações entre os indivíduos ao longo do tempo e é baseada na contínua reciprocidade, ou seja, na noção de que "eu vou fazer isso para você agora porque sei que você vai fazer alguma coisa para mim mais tarde" (ADLER; KWON, 2002; NAHAPIET; GHOSHAL, 1998; DE CAROLIS; SAPARITO, 2006; ROUSSEAU et al., 1998).

As políticas públicas observadas ao nível micro dizem respeito a ações de manutenção de grupos e preservação da cultura regional. Observa-se, no planejamento da faixa de fronteira realizado por parte das SDRs, uma iniciativa em fomentar a produção agropecuária e industrial na região com o intuito de manter a população nos seus municípios (o que fomenta o capital social do tipo bonding). Outra ação 
governamental tem como foco a educação, proporcionando a aproximação de universidades e institutos federais na região oeste catarinense. Por meio dessas instituições de ensino há a possibilidade de qualificação através de cursos técnicos, de graduação, mestrados e doutorados e a manutenção dos profissionais na região. Ao nível dos municípios, podem ser observadas ações específicas para a manutenção de grupos de mães, grupos de mulheres trabalhadoras, grupos de jovens, grupos esportivos, incentivo à formação de estudantes, professores e empresários (SANTA CATARINA, 2012).

\section{Calpitall sociall em mivell meso}

Da mesma forma, foi feita a análise fatorial para o nível meso. O índice de KaiserMeyer-Olkin (KMO) de adequação da amostra foi de 0,752 e o Teste de esfericidade de Bartlett (significativo para 0,000) indicam a fatorabilidade dos dados.

A solução final apresentou três fatores, os quais explicam $46,56 \%$ da variância total. O Alpha de Cronbach para o nível meso foi 0,579. Algumas variáveis foram reagrupadas, considerando-se a validade teórica para a escala.

Em nível meso (diferente do nível micro), o fator mais importante para explicar o capital social foi o tipo bridging (Tabela 2). Este é um resultado esperado: o nível meso está relacionado a uma gama mais ampla de análise, a qual privilegia as relações entre conhecidos e estranhos. Já o nível micro, está mais relacionado à família e aos amigos próximos.

O primeiro fator da análise do capital social no nível meso, o bridging social capital, reflete as relações existentes entre os diferentes grupos no âmbito da comunidade. A maior média nesse grupo (e também do nível meso) é da variável que considera "os colegas de trabalho também amigos" (com 4,42 pontos de média), destacando uma característica da região onde há o estabelecimento de relações entre os diferentes grupos em que o indivíduo está inserido. Além disso, a carga da variável "As pessoas costumam se ajudar" de 0,820 mostra o peso significativo das relações de ponte no contexto em estudo. Apesar disso, a variável "pessoas mais ricas ajudam as mais pobres" obteve o pior desempenho em nível meso (média de 2,65, ficando entre o "discordo em parte" e o "nem concordo, nem discordo"). Apesar do baixo desempenho, esta variável tem menor força explicativa (carga 0,583). Este resultado, apesar de não ser a regra, é compatível com o tipo bridging, pois a horizontalidade das relações de poder é característica do linking (e não necessariamente do bridging).

Tabela 2 - Fatores, Alfa de Cronbach, cargas e médias no nível meso do capital social

\begin{tabular}{|c|c|c|c|c|}
\hline Fator & Alpha de Cronbach & Variável & Carga & Média \\
\hline \multirow{4}{*}{ Bridging } & \multirow{4}{*}{0,628} & 33 - As pessoas costumam se ajudar & 0,820 & 3,69 \\
\hline & & 32 - Pessoas respeitam-se umas às outras & 0,705 & 3,50 \\
\hline & & 31 - Pessoas mais ricas ajudam mais pobres & 0,583 & 2,65 \\
\hline & & 24 - Colegas de trabalho/escola são também amigos & 0,583 & 4,42 \\
\hline \multirow{3}{*}{ Bonding } & \multirow{3}{*}{0,533} & 22 - Pessoas de fora não entendem os costumes & 0,703 & 2,09 \\
\hline & & 29 - Pessoas não aceitam costumes de fora & 0,669 & 2,10 \\
\hline & & 25 - Os moradores dos bairros não se misturam & 0,538 & 1,66 \\
\hline \multirow{3}{*}{ Linking } & \multirow{3}{*}{0,410} & 35 - Os motoristas não respeitam o trânsito & 0,658 & 2,02 \\
\hline & & 26 - Não existem punições para arruaceiros & 0,597 & 1,87 \\
\hline & & 37 - Os bandidos andam à solta & 0,364 & 1,87 \\
\hline
\end{tabular}

Fonte: presente estudo. 
A presença desse fator como o mais forte na explicação do nível de capital social das três SDRs da região Extremo Oeste catarinense demonstra que, no nível meso, as pessoas dessa região possuem maior abertura para se relacionar com pessoas que não fazem parte do seu grupo familiar. As amizades com colegas de trabalho e de escola (média de 4,42), assim como a participação em associações, clubes, cooperativas, também colabora no fortalecimento das "pontes" que ligam os diferentes grupos sociais.

No que diz respeito ao cooperativismo, por exemplo, destaca-se que na região está instalada (e ainda em funcionamento) a mais antiga cooperativa de crédito do Estado de Santa Catarina. A Creditapiranga (atualmente Sicoob Creditapiranga) foi fundada em 1932 com o intuito de auxiliar no processo de colonização. Quando essa cooperativa foi fundada ainda não existia luz elétrica na região, que chegou somente em 1958 (SEHNEM, 2009).

No estado de Santa Catarina, de acordo com a OCESC (2010), em dezembro de 2009 estavam em funcionamento, nos 297 municípios do Estado, 255 cooperativas, que contavam com a participação de 858.671 cooperados e 29.924 empregados. Nos anos de 2008 e 2009, observou-se uma diminuição de 5,48\% no número de cooperativas no Brasil (OCESC, 2010). Embora as informações disponíveis não permitam analisar as regiões em separado, estas ajudam a ilustrar a importância do espírito cooperativo presente na região.

No Brasil, de acordo com dados da Organização das Cooperativas Brasileiras (OCB), nas 27 unidades federativas existem 7.261 cooperativas, as quais geram 199.680 empregos e respondem por $6 \%$ do PIB nacional. Essas cooperativas possuem 6.791 milhões de associados, o que resulta em uma densidade de 26.268 habitantes por cooperativa. Já no Estado de Santa Catarina a proporção é de 28,47 habitantes por cooperativa (GESTÃO COOPERATIVA, 2010).

O capital social do tipo bonding é o segundo fator encontrado do nível meso, o qual pode ser explicado por três variáveis. A variável com maior carga fatorial $(0,703)$, "as pessoas não entendem os costumes", apresentou uma média de 2,09 pontos, demonstrando que os entrevistados discordam desta afirmativa. Assim como estas, as demais variáveis encontradas nesse fator medem, não a presença, mas a ausência de capital social. Por isso, as médias baixas (de 1,66 a 2,10) encontradas representam a discordância dos respondentes para as frases apresentadas; ou seja, indicam a presença de capital social. Com isso, pode-se considerar que, na percepção dos entrevistados, as pessoas de fora aceitam e respeitam os costumes da comunidade, assim como há integração entre pessoas de diferentes classes sociais (ricos e pobres). Visualiza-se, assim, que os aspectos do capital social do tipo bonding, o qual se caracteriza pelos laços existentes entre os grupos que partilham valores semelhantes, estão fortalecidos na região.

Observa-se que as variáveis que se destacaram nesse fator são diferentes das variáveis obtidas nesse mesmo tipo de capital social no nível micro. No nível micro, as variáveis direcionavam-se para a ajuda e cooperação nas relações familiares e com os amigos. No nível meso, as variáveis dizem que os costumes de fora são aceitos, as pessoas entendem os costumes dos outros, e ricos e pobres "se misturam".

No entanto, é preciso destacar que esse tipo de capital social propicia o isolamento dos grupos quando são construídas normas e identidade própria, aspectos que desenvolvem a confiança entre os membros do grupo e um código de linguagem particular, situação fracamente observada na região em estudo. Se os grupos se "fecham" surgem as dificuldades no relacionamento e na cooperação com pessoas de fora dos limites do seu grupo (Webb, 2008; Macke et al., 2010; De Carolis; Saparito, 2006).

O terceiro fator, linking, resultou em três variáveis. As variáveis desse fator (também medindo ausência de capital social) apresentaram as médias mais baixas do nível meso, o que representa um indício de presença de estoques de capital social nas comunidades estudadas. Observa-se que as variáveis do capital social linking dizem respeito à sensação de segurança na cidade e do respeito para com os bens públicos e no trânsito. 
As regiões estudadas estão situadas na fronteira Oeste do Estado de Santa Catarina, onde é latente a sensação de aumento da violência, consequência da variação populacional. O aumento no número de pessoas na região é consequência do crescimento no número de empregados no período de 2003 a 2010, correspondente a $61,8 \%$ (SANTA CATARINA, 2011). Partindo-se desse indicador, é possível considerar pertinente a sensação de insegurança relacionada à ampliação da movimentação humana na região. A injeção econômica que essa movimentação proporciona é um dos fatores que impulsiona a criminalidade, aliada à proximidade da Argentina e do Estado do Paraná.

Os registros da Secretaria de Segurança Pública Catarinense (SANTA CATARINA, 2010), em dados dos anos de 2004 a 2008, demonstram que houve, no ano de 2007, um aumento no número de ocorrências atendidas pelas polícias Civil e Militar no Estado. Apesar disso, a região Oeste de Santa Catarina está numa posição mediana nos índices de criminalidade do Estado: não está situada entre as mais violentas, assim como não se configura dentre as mais seguras, fato que justifica a sensação de segurança dos habitantes da região.

\section{Campitall sociall em mivell macro}

O KMO para os dados rodados no nível macro resultou em 0,615 , com o valor da significância $p=0,000$, o que permite concluir que as variáveis são correlacionadas e a fatorabilidade é plausível. A solução final apresentou três fatores, com 48,56\% da variância explicada.

O linking social capital foi o primeiro fator encontrado no nível macro, o qual consiste em variáveis que enfatizam a relação entre as nações ("ajudar vítimas de outros países", com carga fatorial de 0,711), bem como a percepção de justiça e solidariedade dentro do país ("ajudar pessoas carentes por meio de programas sociais", com carga de 0,711 ). Pode-se considerar que este fator ficou o mais forte na explicação do capital social em nível macro.

De modo geral, estas variáveis estão relacionadas ao governo: a ajuda aos pobres e ajuda humanitária a outros países. É importante notar que há poucos instrumentos para medir o capital social que incluem variáveis sobre o desempenho do governo e da satisfação do cidadão. Abrangendo os setores privado e público e também o comportamento de cidadania, estas variáveis juntas, apontam as condições

Tabela 3 - Fatores, Alfa de Cronbach, cargas e médias no nível macro do capital social

\begin{tabular}{|c|c|c|c|c|}
\hline Fator & Alpha de Cronbach & Variável & Carga & Média \\
\hline \multirow[t]{2}{*}{ Linking } & \multirow[t]{2}{*}{0,487} & $\begin{array}{l}\text { 53. O governo brasileiro deve ajudar as pessoas } \\
\text { carentes por meio de programas sociais }\end{array}$ & 0,749 & 3,23 \\
\hline & & 45 - Brasil deve ajudar vítimas de outros países & 0,711 & 3,95 \\
\hline \multirow{3}{*}{ Bridging } & \multirow{3}{*}{0,467} & $\begin{array}{l}56 \text { - Quem mora no Brasil aprende a respeitar todas } \\
\text { as raças }\end{array}$ & 0,758 & 3,23 \\
\hline & & 58 - Sinto orgulho de ser brasileiro & 0,657 & 4,32 \\
\hline & & 50 - No Brasil, as pessoas são honestas & 0,599 & 3,05 \\
\hline \multirow{4}{*}{ Bonding } & \multirow{4}{*}{0,465} & $\begin{array}{l}54 \text { - O Brasil não deve se preocupar em apaziguar } \\
\text { conflitos em outros países }\end{array}$ & 0,661 & 2,00 \\
\hline & & $\begin{array}{l}51 \text { - O Brasil não deveria se envolver em assuntos de } \\
\text { outros países }\end{array}$ & 0,653 & 2,02 \\
\hline & & 57 - No Brasil, só os pobres vão para a cadeia & 0,610 & 1,83 \\
\hline & & 52 - Eu não confio na justiça brasileira & 0,539 & 2,03 \\
\hline
\end{tabular}

Fonte: presente estudo. 
para alargar a participação social e construção da comunidade, em outras palavras, o reforço da governança.

Este resultado indica que, provavelmente, há, nesta região, governos abertos às demandas dos estratos mais baixos da pirâmide social. A capacidade de alavancar recursos, ideias e informações de instituições formais na comunidade é uma funçãochave desse tipo de capital social.

O segundo fator encontrado no nível macro do capital social foi o bridging. Esse fator resultou em três variáveis, as quais enfatizam as percepções sobre o comportamento do brasileiro ("quem mora no Brasil aprende a respeitar todas as raças", com carga de 0,752; "sinto orgulho de ser brasileiro", com 0,657; e "no Brasil, as pessoas são honestas", com 0,599).

As variáveis deste fator demonstram a importância dos sentimentos de nacionalismo, a tolerância à diversidade e a presença de honestidade. É possível verificar, neste caso, que a maioria dos entrevistados concordou com as afirmativas (apesar da variável "honestidade" apresentar um desempenho mais baixo). Estes resultados indicam que há um estoque de capital social de conexão na forma de abertura para a confiança, o qual poderá ser mobilizado em prol do coletivo.

Essa relação pode ser explicada também pelo fato da região ser fronteira do Brasil com a Argentina: o sentimento de pertencimento e de patriotismo é mais aflorado, até mesmo como forma de identidade nacional. A convivência na fronteira tem se mostrado pacífica nas últimas décadas e intensifica-se em períodos de valorização da moeda brasileira, quando as compras e viagens ao país vizinho se tornam vantajosas financeiramente.

O terceiro fator encontrado no nível macro foi o bonding, formado por variáveis que medem a ausência de capital social e apresentaram médias baixas (entre 1,83 e 2,03 ), indicando que as pessoas discordam das afirmativas.

Este fator agrupou variáveis que tentam mostrar como uma sociedade está aberta a cooperar com "estranhos" ("o Brasil deve se preocupar com conflitos em outros países") e que a confiança no país está melhorando ("os ricos também vão para a cadeia" e "é possível confiar na justiça brasileira"). Esta cooperação aparece por meio de ações e políticas estatais e destaca a importância das sociedades em estabelecer normas de altruísmo impessoal (Halpern (2008) usa essa expressão com base no conceito de idealismo de Hegel). A sensação de viver em um bom lugar, sem prejuízo também é um indicador de altruísmo impessoal, porque reforça a identidade, mesmo em um contexto muito amplo e complexo, que é o de nação.

Tem-se, por parte do governo federal, a iniciativa de integração da faixa de fronteira por meio de políticas públicas discutidas para implementação através das SDRs dessa região. O planejamento estratégico, que está em fase de desenvolvimento, foca ações em educação, agricultura, infraestrutura, política, economia, dentre outras (SANTA CATARINA, 2012). O propósito do governo com essa iniciativa é a manutenção e a atração das pessoas para a região da faixa de fronteira, assim como o desenvolvimento dessa região que, historicamente possui um atraso em relação ao restante do país.

\section{Comsidlerenções frimaris}

A mensuração do capital social é uma prática delicada e que tem fomentado um vasto campo de pesquisa. A disponibilidade dos dados é limitada (assim como sua obtenção) e sua interpretação exige cautela. Os dados quantitativos precisam ser interpretados sob a luz de diversas fontes bibliográficas e estudos de casos, a fim de que seus resultados possam ser compreendidos.

Para atingir o objetivo desse estudo, ou seja, a mensuração do nível do capital social nas três SDRs da região Extremo Oeste Catarinense, foi utilizada a técnica estatística de análise fatorial. Também, a fim de complementar a análise e de gerar novos insights foram analisadas quais variáveis de identificação do respondente 
(sociais, econômicas e demográficas) são estatisticamente significativas para cada um dos fatores encontrados.

Os resultados da análise mostraram que o capital social é mais expressivo na SDR de Itapiranga (micro bonding, macro bridging e macro linking), representado respectivamente pelos laços fortes, confiança e governança local. Na SDR de Dionísio Cerqueira o coletivismo mostra-se como uma característica bastante presente (micro linking) além dos laços fracos, especificidade presente nas regiões de fronteira (micro bridging). Na SDR de São Miguel do Oeste, da mesma forma que na SDR de Dionísio Cerqueira, observou-se que há maior presença de laços fracos (micro bridging).

Nas três regiões analisadas é possível observar que há grande influência dos costumes e tradições dos municípios de origem, na manutenção de algumas práticas do cotidiano. É possível perceber resquícios da colonização nos diferentes aspectos da vida dos habitantes da região. Um exemplo, na região da SDR de Itapiranga existe o hábito da leitura da revista "Skt. Paulusblatt", editada em língua alemã e impressa em Porto Alegre (RS). Essa revista, nas novas colônias representa um forte vínculo com as colônias velhas, uma vez que, para muitos colonos, o retorno às terras de origem a fim de visitar seus patrícios e rever familiares costumava levar décadas para ocorrer. Para outros, esse seria (e ainda é) o único elo com seu passado, pois seu retorno às colônias velhas jamais irá acontecer (SEHNEM, 2009).

A abordagem do capital social muito tem a contribuir para a compreensão do desenvolvimento das regiões; ele pode ajudar na identificação de políticas que devem ser evitadas, sob o risco de provocar um efeito não desejado. Neste sentido, pode-se concluir que devem ser fortalecidas as políticas públicas que proporcionam um equilíbrio dos tipos de capital social (bonding, bridging e linking), já que o favorecimento de um, em detrimento de outro, fomenta a formação de grupos isolados, cujas divergências de interesses podem gerar desequilíbrios sociais e prejuízos à confiança. Assim, são consideradas importantes as ações que promovam as atividades em grupos, inserindo as pessoas no contexto de discussão de ideias e manutenção da cultura e hábitos das comunidades, tais como grupos de idosos, grupos de mães, grupos de mulheres agricultoras, grupos de damas, grupos promovidos pelos clubes, a exemplo de grupos de jogos (bochas, baralho, bolão...) entre outras possibilidades. Com isso há a possibilidade de preservação e manutenção das características culturais das comunidades, além da integração entre diferentes grupos.

Referê̂ncials

AAKER, D. A.; KUMAR, V.; DAY, G. S. Pesquisa de marketing. 2. ed. São Paulo: Atlas, 2004.

ABRAMOVAY, R. O capital social dos territórios: repensando o desenvolvimento rural. Economia Aplicada, v. 4, n. 2, p. 379-97, abr./jun. 2000.

ADLER, P; KWON, S. Social capital: prospects for a new concept. Academy of Management Review. v. 27, n. 1, p. 17-40, Jan. 2002.

ALBAGLI, S; MACIEL, M. L. Capital social e empreendedorismo local: proposição de políticas para a promoção de sistemas produtivos locais de micro, pequenas e médias empresas. Rede de sistemas produtivos e inovativos locais. Rio de Janeiro; UFRJ, 2002.

BANCO MUNDIAL. Measuring social capital. New York, 2009. Disponível em: <http://web.worldbank.org/WBSITE/EXTERNAL/TOPICS/EXTSOCIALDEVELOPMENT/ EXTTSOCIALCAPITAL/0, menuPK:401021 pagePK:149018 piPK:149093 theSite PK:401015,00.html>. Acesso em: 7 dez. 2009.

BANDEIRA, P. S. As raízes históricas do declínio da região sul. In: ALONSO, J. A. F.; BENETTI, M. D.; BANDEIRA, P. S. Crescimento econômico da região sul do Rio Grande do Sul: causas e perspectivas. Porto Alegre: FEE, 1994. 
BETTERTOGETHER. The report of the saguaro seminar: civic engagement in America. Cambridge: Harvard University, [200?]. Disponível em: <http://www. bettertogether.org/bt_report.pdf>. Acesso em: 30 nov 2009.

BOURDIEU, P. O poder simbólico. 3. ed. São Paulo: Bertrand Brasil, 2000.

BOURDIEU, P. Razões práticas: sobre a teoria da ação. Campinas: Papirus, 1996.

BOURDIEU, P. The forms of capital. In: RICHARDSON, J. G. (ed.). Handbook of theory and research for the sociology of education. New York: Greenwood, 1986. p. 241-58.

COLEMAN, J. S. Social capital in the creation of human capital. American Journal of Sociology, v. 94, suppl, p. S95-120, 1988.

COLEMAN, J. S. Foundations of social theory. Cambridge: Harvard University Press, 1990.

CRAWFORD, A. Fixing broken promises?: neighbourhood wardens and social capital. Urban Studies, v. 43, n. 5/6, p. 957-76, May 2006.

D'ARAÚJO, M. C. S. Capital social. Rio de Janeiro: Jorge Zahar, 2003.

DE CAROLIS, D. M.; SAPARITO, P. Social capital, cognition, and entrepreneurial opportunities: a theoretical framework. Entrepreneurship Theory and Practice, v. 30, n.1, p. 41-56, Jan. 2006.

EIDT, P. Os sinos se dobram por Alfredo. Chapecó: Argos, 2009.

FUKUYAMA, F. A grande ruptura: a natureza humana e a reconstituição da ordem social. Rio de Janeiro: Rocco, 2000.

GAAG, M. V. D. ; SNIJDERS, T. A. B. A comparison of measures for individual social capital. Groningen: University of Groningen, 2003.

GESTÃO COOPERATIVA. Cooperativismo. Disponível em: <http://gestaocooperativa. com.br/cooperativismo/>. Acesso em: 22 dez 2010.

GRANOVETTER, M. S. Economic action and social structure: the problem of embeddedness. American Journal of Sociology, v. 91, n. 3, p. 481-510, Nov. 1985.

HAIR JUNIOR, J. F. et al. Fundamentos de métodos de pesquisa em administração. Porto Alegre: Bookman, 2007.

HALPERN, D. Social capital. Cambridge: Polity, 2008.

KLIKSBERG, B. Capital social y cultura, claves esenciales del desarrollo. Revista CEPAL, n. 69, p. 85-102, dic. 1999.

LEE, L. T.-S.; SUKOCO, B. M. The effects of entrepreneurial orientation and knowledge management capability on organizational effectiveness in Taiwan: the moderating role of social capital. International Joumal of Management, v. 24, n. 3, p. 459-572, sept. 2007.

MACKE, J.; SARATE, J. A. R.; DAMACENA, C. Avaliação do capital social em uma cidade gaúcha: a percepção dos estudantes de administração. REAd Revista Eletrônica de Administração, v. 16, n. 3, p. 385-9, 2010.

MACKE, J.; GENARI, D.; FACCIN, K. Social capital in brazilian wine industry networks. African Journal of Business Management, v. 6, n. 19, p. 5990-8, May 2012.

MALHOTRA, N. Pesquisa de marketing: uma orientação aplicada. 3. ed. Porto Alegre: Bookman, 2007.

MONASTÉRIO, L. M. Capital social e a região Sul do Rio Grande do Sul. 2002. Tese (Doutorado em Desenvolvimento Econômico) - Curitiba: Universidade Federal do Paraná, 2002.

MONASTÉRIO, L. M. Medindo capital social: uma análise das regiões do Rio Grande do Sul. In: CORREA, S. M. S. Capital social e desenvolvimento regional. Santa Cruz do Sul: EDUNISC, 2003. p. 61-84. 
NAHAPIET, J.; GHOSHAL, S. Social capital, intellectual capital and the organizational advantage. Academy of Management Review, v. 23, n. 2, p. 242-66, Apr. 1998.

NATIONAL STATISTICS. Social Analysis and Reporting Division. Social capital: a review of the literature. London: Office for National Statistics, 2001.

ONYX, J.; BULLEN, P. Measuring social capital in five communities. Journal of Applied Behavioral Science, v. 36, n. 1, p. 23-42, Mar. 2000.

OCESC - ORGANIZAÇÃO DAS COOPERATIVAS DO ESTADO DE SANTA CATARINA. Estatísticas do cooperativismo de Santa Catarina. Disponível em: <http://www. ocesc.org.br/cooperativas/download/06_03_2006_estatisticas.pdf>. Acesso em: 22 nov. 2010.

PASSEY, A.; LYONS, M. Nonprofits and social capital measurement through organizational surveys. Nonprofit Management \& Leadership, v. 16, n. 4, p. 481-95, 2006.

PESTANA, M.; GAGEIRO, J. Análise de dados para ciências sociais. Lisboa: Sílabo, 2000.

PUTNAM, R. Bowling alone: the collapse and revival of american community. New York: Simon \& Schuster, 2000.

PUTNAM, R. D.; LEONARDI, R.; NANETTI, R. Comunidade e democracia: a experiência da Itália moderna. 3. ed. Rio de Janeiro: Fundação Getúlio Vargas, 2002.

ROUSSEAU, D. et al. Not so different after all: a cross-discipline view of trust. Academy of Management Review, v. 23, n. 3, p. 393-404, July 1998.

SABATINI, F. Social capital and the quality of economic development. Kyklos. v. 61, n. 3, p. 466-9, Aug. 2008.

SANTA CATARINA. Secretaria de Desenvolvimento Regional de São Miguel do Oeste. Municípios da SDR. Disponível em: <http://www.sdrs.sc.gov.br/ sdrsaomigueldooeste/municipios-da-sdr>. Acesso em: 28 jul. 2012.

SANTA CATARINA. Secretaria de Estado da Fazenda. Número de empregados segundo os setores econômicos e municípios de Santa Catarina: 2000 2010. Florianópolis, 2011. Disponível em: <http://www.sef.sc.gov.br/index2. php?option=com_docman\&task=doc $>$. Acesso em: 28 jul. 2012.

SANTA CATARINA. Secretaria de Segurança Pública de Santa Catarina. Estatística criminal. Disponível em: <http://www.ssp.sc.gov.br/index.php?option=com_ docman\&task=cat_view\&gid=91\&Itemid=174>. Acesso em 27 de dezembrō de 2010 .

SEHNEM, A. Oktoberfest de Itapiranga: 30 anos de história. São Miguel do Oeste: McLee, 2009.

VERSCHOORE FILHO, J. R. S. Metade sul: uma análise das políticas públicas para o desenvolvimento regional no Rio Grande do Sul. Porto Alegre, 2000. Dissertação (Mestrado em Administração Pública) - Porto Alegre: UFRGS, 2000.

WEBB, C. Measuring social capital and knowledge networks. Journal of Knowledge Management, v. 12, n. 5, p. 65-78, 2008.

Submissão: 18/04/2013
Aprovação: $30 / 03 / 2014$ 